\title{
Chapter 27 \\ Temperature Sensitivity of Canopy \\ Photosynthesis Phenology in Northern \\ Ecosystems
}

\author{
Shuli Niu, Yuling Fu, Lianhong Gu, and Yiqi Luo
}

\begin{abstract}
Northern Hemisphere terrestrial ecosystems have been recognized as areas with large carbon uptake capacity and sinks and are sensitive to temperature change. However, the temperature sensitivity of ecosystem carbon uptake phenology in different biomes of northern ecosystems has not been well explored. In this study, based on our previous effort in characterizing canopy photosynthesis phenology indices, we analyzed how these phenology indices responded to temperature changes by using spatial temperature variability in the temperate and boreal ecosystems in the north hemisphere. Eddy covariance flux measurements of canopy photosynthesis were used to examine the temperature sensitivity of canopy photosynthesis phenology in different biomes and seasons (spring and autumn). Over all the 68 sites, the upturning day, peak recovery day, peak recession day, and senescence day of canopy photosynthesis were all sensitive to mean annual air temperature. Sites with higher mean annual air temperature had earlier carbon uptake and peak recovery day, but later ending of carbon uptake and peak recession
\end{abstract}

Equal contribution

S. Niu $(\bowtie)$

Institute of Geographical Sciences and Natural Resources Research,

Chinese Academy of Sciences, Beijing, China

Department of Microbiology and Plant Biology, University of Oklahoma,

Norman, OK 73019, USA

e-mail: sniu@ou.edu

Y. Fu

Institute of Geographical Sciences and Natural Resources Research,

Chinese Academy of Sciences, Beijing, China

L. $\mathrm{Gu}$

Environmental Sciences Division, Oak Ridge National Laboratory,

Oak Ridge, TN 37831, USA

Y. Luo

Department of Microbiology and Plant Biology, University of Oklahoma,

Norman, OK 73019, USA 
day. As a consequence, effective growing season length was linearly increased with temperature for all the biomes. Spring phenology indices were more sensitive to temperature change than fall phenology. Besides phenology, peak canopy photosynthesis capacity was also linearly increased with temperature, and contributed even more to annual carbon assimilation changes than growing season length. These findings suggest a predominant temperature controls on annual carbon assimilation in northern ecosystems by changing both canopy photosynthesis phenology and physiology. The temperature sensitivity of canopy photosynthesis phenology and physiology indices revealed in this study are helpful to develop better models to predict impacts of global climate change on vegetation activities.

\subsection{Introduction}

Temperature strongly influences terrestrial ecosystem carbon cycle by directly changing physiological activities and indirectly mediating phenology. In temperate and boreal ecosystems, phenology play even more important role in controlling the seasonal onset and ending of the carbon uptake, with a consequent impact on net ecosystem production (Goulden et al. 1996; Piao et al. 2007; Baldocchi 2008; Barr et al. 2009). So, it is expected that the unprecedented climate warming will significantly alter growing season length by changing community phenology, with a consequence of driving annual carbon uptake in northern terrestrial ecosystems (Menzel and Fabian 1999; Peñuelas and Filella 2001; Sherry et al. 2007).

Previous studies have documented a correlation between earlier spring phenology and rising temperature in recent years (Cleland et al. 2007). It is reported that the first leaf dates and last frost dates were 1.2 and 1.5 days earlier per decade, respectively, for Northern Hemisphere temperate land areas from 1955 to 2002 (Schwartz et al. 2006). However, very recently, it is reported that spring warming results in delayed spring phenology on the Tibetan Plateau due to later fulfillment of chilling requirements ( $\mathrm{Yu}$ et al. 2011). Comparing with the spring phenology in response to temperature change, autumn phenology has even more inconsistent response to autumn warming, with early (Piao et al. 2008) or late (Piao et al. 2007; Dragoni et al. 2011) ending of carbon uptake. Most of these previous studies on the relationship between climate change and phenology are based on remote sensing data, model simulation, or observational network of species-specific plant phenophases, while the direct evidence of changes in canopy carbon uptake phenology and its relationship with temperature change are far from clear.

In this chapter, we continued our previous effort (Gu et al. 2003, 2009) and used a systematic methodology to identify the beginning and ending dates of canopy carbon uptake as well as the length of growing season as indicated by canopy carbon uptake period in the northern ecosystems and explored their temperature sensitivities. We derived a series of phenological indices that can be used to characterize canopy photosynthetic phenology. The advance of the eddy covariance technique (Baldocchi and Wilson 2001; Baldocchi 2003) provides a tool amenable for studying the dynamics of plant community photosynthesis (Falge et al. 2002; Gu et al. 2003, 2009). We have used our analytical framework to successfully analyzed 
plant community photosynthesis (Gu et al. 2003, 2009). In this chapter, we have two objectives : (1) to explore the temperature responses of the critical phenology stages of canopy photosynthesis in different biomes and seasons; (2) to examine the controls of effective growing season length and peak photosynthetic capacity in regulating annual carbon accumulation in different biomes. An extended analysis allows us to develop a comprehensive picture on how the canopy photosynthetic phenology indices of plant community respond to temperature change in different vegetation types.

\subsection{Sites and Data Used in the Present Study}

We used data from the FLUXNET 'La Thuile' dataset (http://www.fluxdata.org), in which the $30 \mathrm{~min}$ and daily eddy covariance measurements (net ecosystem exchange, $\mathrm{NEE}$, of $\mathrm{CO}_{2}$ ) have been standardized, gap-filled and partitioned to the component fluxes of ER and GPP using a set of common algorithms (Papale et al. 2006; Moffat et al. 2007). In this dataset, for each site, the meteorological data (air and soil temperature, precipitation, humidity, vapor pressure deficit, global radiation and etc.) as well as the carbon fluxes data (NEE, ecosystem respiration (ER), and gross primary productivity (GPP)) were provided. From the 253 sites with available data, we identified those temperate or boreal ecosystems because in these summer active ecosystems, temperature rather than water availability is considered the main drivers for seasonal variation in phenology. We studied 68 sites with 263 site-years data of three major vegetation types in northern ecosystems, including 22 deciduous broad leaf foresee (DBF), 29 evergreen needle leaf forest (ENF), and 17 grasslands (Table 27.1). These sites range from $30.85^{\circ} \mathrm{N}$ to $69.14^{\circ} \mathrm{N}$ (Table 27.1). The sites without active photosynthesis throughout a year or without a full formant season, or with large data gaps during the growing season were not included in this study. Our analysis was based on canopy photosynthetic rates which were derived from NEE in the same way as described in detail in Gu et al. (2003).

\subsection{Quantifying Plant Community Photosynthetic Phenology}

We used the same method with those in Gu et al. (2009) to quantify the canopy photosynthetic phenology. We first fit the instantaneous canopy photosynthetic rate which was derived from the NEE measurement to the following equation. The canopy photosynthetic capacity (CPC) is defined as the maximal gross photosynthetic rate at the canopy level when the environmental conditions (e.g. light, moisture, and temperature) are non-limiting for the time of a year under consideration (Fig. 27.1).

$$
A(t)=y_{0}+\frac{a_{1}}{\left[1+\exp \left(-\frac{t-t_{01}}{b_{1}}\right)\right]^{c_{1}}}-\frac{a_{2}}{\left[1+\exp \left(-\frac{t-t_{02}}{b_{2}}\right)\right]^{c_{2}}}
$$

where $A(t)$ is the CPC in day $t ; y_{0}, a_{1}, a_{2}, b_{1}, b_{2}, c_{1}, c_{1}, t_{01}$, and $t_{02}$ are empirical parameters to be estimated. 
Table 27.1 Main site characteristics, climatic indexes, and studied periods of flux sites used in this analysis

\begin{tabular}{|c|c|c|c|c|c|}
\hline Site & Lat. & Long. & Years & Vegetation & Climate \\
\hline$\overline{\text { AT-Neu }}$ & 47.12 & 11.32 & $2002-2006$ & GRA & Temperate \\
\hline Be-Vie & 50.31 & 6.00 & 1997-2006 & ENF & Temperate \\
\hline $\mathrm{CA}-\mathrm{Ca} 2$ & 49.87 & -125.29 & $2002-2005$ & ENF & Temperate \\
\hline $\mathrm{CA}-\mathrm{Ca} 3$ & 49.53 & -124.90 & 2002-2004 & ENF & Temperate \\
\hline CA-Let & 49.71 & -112.94 & 1999-2005 & GRA & Temperate \\
\hline CA-Man & 55.88 & -98.48 & $1995-2003$ & ENF & Boreal \\
\hline CA-Mer & 45.41 & -75.52 & 1999-2005 & GRA & Temperate \\
\hline CA-NS1 & 55.88 & -98.48 & 2003-2004 & ENF & Boreal \\
\hline CA-NS2 & 55.91 & -98.52 & 2002-2004 & ENF & Boreal \\
\hline CA-NS3 & 55.91 & -98.38 & 2002-2005 & ENF & Boreal \\
\hline CA-NS4 & 55.91 & -98.38 & 2003-2004 & ENF & Boreal \\
\hline CA-NS5 & 55.86 & -98.49 & 2002-2005 & ENF & Boreal \\
\hline CA-NS6 & 55.92 & -98.96 & $2002-2005$ & DBF & Boreal \\
\hline CA-NS7 & 56.64 & -99.95 & 2003-2005 & GRA & Boreal \\
\hline CA-Oas & 53.63 & -106.20 & 1997-2005 & DBF & Boreal \\
\hline CA-Obs & 53.99 & -105.12 & 2000-2005 & ENF & Boreal \\
\hline CA-Ojp & 53.92 & -104.69 & 2000-2005 & ENF & Boreal \\
\hline CA-Qcu & 49.27 & -74.04 & 2002-2006 & $\mathrm{ENF}$ & Boreal \\
\hline CA-Qfo & 49.69 & -74.34 & 2004-2006 & ENF & Boreal \\
\hline CA-TP4 & 42.71 & -80.36 & 2004-2005 & ENF & Temperate \\
\hline CN-Do1 & 31.58 & 121.96 & 2005 & GRA & Subtropical \\
\hline CN-Du1 & 42.05 & 116.67 & 2004-2005 & GRA & Temperate \\
\hline CN-Xfs & 44.13 & 116.33 & 2004-2006 & GRA & Temperate \\
\hline DE-Bay & 50.14 & 11.87 & 1997-1998 & ENF & Temperate \\
\hline DE-Hai & 51.08 & 10.45 & 2000-2006 & DBF & Temperate \\
\hline DE-Meh & 51.28 & 10.66 & 2004-2006 & GRA & Temperate \\
\hline DE-Tha & 50.96 & 13.57 & 1997-2005 & ENF & Temperate \\
\hline DE-Wet & 50.45 & 11.46 & 2002-2005 & ENF & Temperate \\
\hline DK-Sor & 55.49 & 11.65 & 1997-2006 & DBF & Temperate \\
\hline FI-Hyy & 61.85 & 24.29 & 1997-2006 & ENF & Boreal \\
\hline FI-Kaa & 69.14 & 27.30 & 2000-2006 & GRA & Boreal \\
\hline FI-Sod & 67.36 & 26.64 & 2000-2006 & ENF & Boreal \\
\hline HU-Bug & 46.69 & 19.60 & 2003-2006 & GRA & Temperate \\
\hline IT-Lav & 45.96 & 11.28 & 2001-2006 & ENF & Temperate \\
\hline IT-Mbo & 46.02 & 11.05 & 2003-2006 & GRA & Temperate \\
\hline IT-Non & 44.69 & 11.09 & 2001-2006 & DBF & Temperate \\
\hline IT-Ren & 46.59 & 11.43 & 1999-2006 & ENF & Temperate \\
\hline IT-Ro1 & 42.41 & 11.93 & 2001-2004 & DBF & Subtropical \\
\hline IT-Ro2 & 42.39 & 11.92 & 2002-2006 & DBF & Subtropical \\
\hline JP-Tak & 36.15 & 137.42 & 1999-2004 & DBF & Temperate \\
\hline JP-Tom & 42.74 & 141.52 & 2001-2003 & DBF & Temperate \\
\hline NL-Cal & 51.97 & 4.93 & 2003-2006 & GRA & Temperate \\
\hline RU-Che & 68.61 & 161.34 & 2003-2005 & ENF & Boreal \\
\hline RU-Fyo & 56.46 & 32.92 & 1999-2006 & ENF & Temperate \\
\hline RU-Zot & 60.80 & 89.35 & 2002-2004 & ENF & Boreal \\
\hline
\end{tabular}


Table 27.1 (continued)

\begin{tabular}{llllll}
\hline Site & Lat. & Long. & Years & Vegetation & Climate \\
\hline SE-Fla & 64.11 & 19.46 & $1997-2002$ & ENF & Boreal \\
SE-Nor & 60.09 & 17.48 & $1996-2005$ & ENF & Temperate \\
UK-Ham & 51.12 & -0.86 & $2004-2005$ & DBF & Temperate \\
US_Goo & 34.25 & -89.87 & $2004-2005$ & GRA & Subtropical \\
US-ARB & 35.55 & -98.04 & $2005-2006$ & GRA & Temperate \\
US-Bar & 44.06 & -71.29 & $2004-2005$ & DBF & Temperate \\
US-Bn1 & 63.92 & -145.38 & 2003 & ENF & Boreal \\
US-Dk2 & 35.97 & -79.10 & $2003-2005$ & DBF & Subtropical \\
US-Ha1 & 43.54 & -72.17 & $1992-2006$ & DBF & Temperate \\
US-Ho1 & 45.20 & -68.74 & $1996-2004$ & ENF & Temperate \\
US-Ho2 & 45.21 & -68.75 & $1999-2004$ & ENF & Temperate \\
US-IB2 & 41.84 & -88.24 & $2006-2007$ & GRA & Temperate \\
US-LPH & 42.54 & -72.19 & $2003-2004$ & DBF & Temperate \\
US-MMS & 39.32 & -86.41 & $1999-2005$ & DBF & Subtropical \\
US-Moz & 38.74 & 92.2 & $2005-2006$ & DBF & Subtropical \\
US-NC1 & 35.81 & -76.71 & $2005-2006$ & GRA & Subtropical \\
US-NR1 & 40.03 & -105.55 & $1999-2003$ & ENF & Boreal \\
US-Oho & 41.55 & -83.84 & $2004-2005$ & DBF & Temperate \\
US-Pfa & 45.95 & -90.27 & $1997-2003$ & DBF & Temperate \\
US-Syv & 46.24 & -89.35 & $2002-2005$ & DBF & Temperate \\
US-UMB & 45.56 & -84.71 & $1999-2003$ & DBF & Temperate \\
US-WBW & 35.96 & -84.29 & $1995-1999$ & DBF & Subtropical \\
US-WCr & 45.81 & -90.08 & $1999-2006$ & DBF & Temperate \\
\hline
\end{tabular}

Fig. 27.1 Illustration of the canopy photosynthetic capacity $(C P C)$

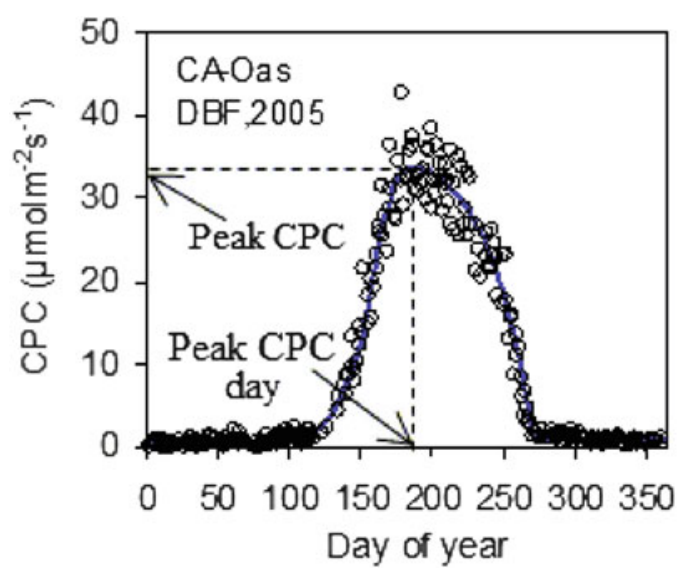

In practice, the following iterative procedures were used to estimate the parameters in Eq. (27.1).

$a$. Compute hourly or half-hourly (depending on observational time steps) canopy photosynthetic rates from NEE measurements. 
$b$. Select the largest value from each day to form a time series of the daily maximal canopy photosynthetic rate. The time series shall cover the complete seasonal cycle.

c. Fit Eq. (27.1) to the obtained time series.

$d$. For each point in the time series, compute the ratio of the daily maximal canopy photosynthetic rate to the value predicted by Eq. (27.1) for the corresponding day with the fitted parameters.

e. Conduct the Grubb's test (NIST/SEMATECH 2006) to detect if there is an outlier in the obtained ratios.

$f$. If an outlier is detected, remove this outlier and go to Step $c$.

$g$. If no outlier is found, remove the data points whose ratios are at least one standard deviation $(1 \sigma)$ less than the mean ratio. The remaining dataset is considered to consist of the canopy photosynthetic capacity at various times of the growing season.

h. Fit Eq. (27.1) to the time series of the CPC. Equation (27.1) with the obtained parameters depict the seasonal cycle of plant community photosynthesis and is then used for further analyses (see the next section).

\subsubsection{Characterizing the Dynamics in CPC}

The growth rate $(k)$ of the $\mathrm{CPC}$ is the derivative of the canopy photosynthetic capacity with respect to the day $(t)$ of year:

$$
\begin{aligned}
k(t) & =\frac{d A(t)}{d t} \\
& =\frac{a_{1} c_{1}}{b_{1}} \frac{\exp \left(-\frac{t-t_{01}}{b_{01}}\right)}{\left[1+\exp \left(-\frac{t-t_{01}}{b_{01}}\right)\right]^{1+c_{1}}}-\frac{a_{2} c_{2}}{b_{2}} \frac{\exp \left(-\frac{t-t_{02}}{b_{02}}\right)}{\left[1+\exp \left(-\frac{t-t_{02}}{b_{02}}\right)\right]^{1+c_{2}}}
\end{aligned}
$$

The maximal growth rate of canopy photosynthetic capacity is termed 'Peak Recovery Rate' and denoted by $k_{P R R}$; the day on which this rate occurs is termed 'Peak Recovery Day' and denoted by $t_{P R D}$ (Fig. 27.2):

$$
k_{P R R}=k\left(t_{P R D}\right)
$$

We further define 'Recovery Line' (RL) as the line that passes through the maximum with a slope of $k_{P R R}$. Its equation can be written as follows:

$$
A_{\mathrm{RL}}(t)=k_{P R R} t+A\left(t_{P R D}\right)-k_{P R R} t_{P R D}
$$

where $A_{R L}$ is the canopy photosynthetic capacity predicted by the Recovery Line. Similarly, we term the most negative growth rate of canopy photosynthetic capacity 

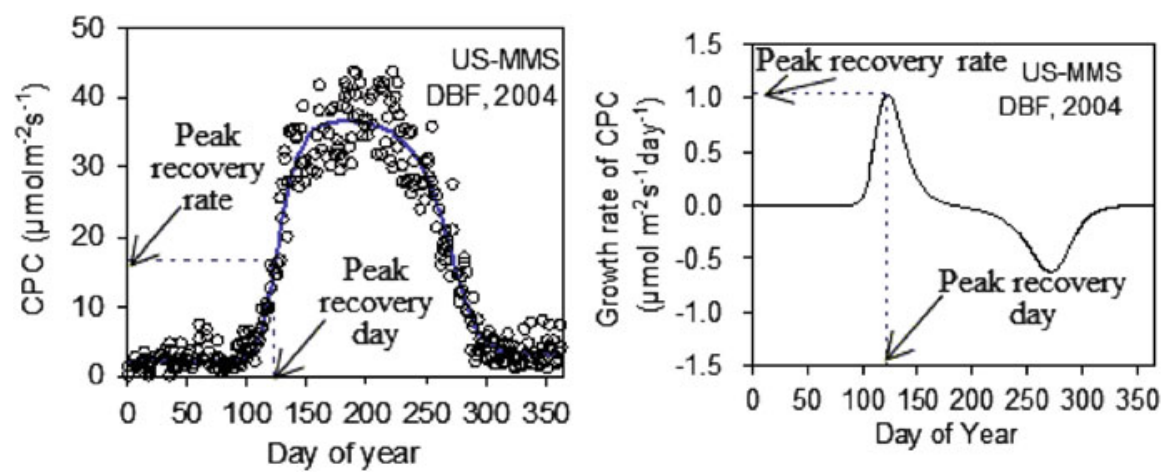

Fig. 27.2 Illustration of the peak recovery rate $\left(k_{P R R}\right)$ and peak recovery day $\left(t_{P R D}\right)$

'Peak Senescence Rate' and denote it by $k_{P S R}$ and the day on which $k_{P S R}$ occurs 'Peak Senescence Day' and denote it by $t_{P S D}$ :

$$
k_{P S R}=k\left(t_{P S D}\right)
$$

Accordingly, we define 'Senescence Line' (SL) as the line that passes through the minimum (the most negative) with a slope of $k_{P S R}$ and describe it by the following equation:

$$
A_{S L}(t)=k_{P S R} t+A\left(t_{P S D}\right)-k_{P S R} t_{P S D}
$$

where $A_{S L}$ is the canopy photosynthetic capacity predicted by the Senescence Line.

It is very difficult to determine $t_{P R D}$ and $t_{P S D}$ analytically from the Eq. (27.1). However, they can be approximated by:

$$
t_{P R D} \approx t_{01}+b_{1} \ln \left(c_{1}\right)
$$

and

$$
t_{P S D} \approx t_{02}+b_{2} \ln \left(c_{2}\right)
$$

Equation (27.7) is obtained by setting the derivative of the first term in Eq. (27.2) with respect to $t$ to zero and solve for $t$ where the first term is at maximum; Eq. (27.8) is obtained by setting the derivative of the second term in Eq. (27.2) with respect to $t$ to zero and solve for $t$ where the second term is at maximum. Equations (27.7) and (27.8) hold because when $t$ is small, the second term in Eq. (27.2) is close to zero and when $t$ is large, the first term is close to zero. Alternatively, one could simply compute the value of $k$ for each day of the year and pick up the maximum and the minimum as we did in this study. 


\subsubsection{Characterizing Canopy Photosynthetic Potential}

We calculated the area under the curve of $A(t)$, which is an indicator of how much carbon dioxide can be potentially assimilated by a plant community over a complete cycle of photosynthesis in a year. As in Gu et al. (2009), we term this area as 'Carbon Assimilation Potential' $(u)$ :

$$
u=\int_{t_{\text {start }}}^{t_{\text {end }}} A(t) d t
$$

For the purpose of calculating the carbon assimilation potential $u$, it is not necessary to determine $t_{\text {start }}$ and $t_{\text {end }}$ exactly as long as one whole seasonal cycle of photosynthesis is included between $t_{\text {start }}$ and $t_{\text {end }}$. This is because the two tails of $A$ contribute little to $u$. Therefore we conveniently set $t_{\text {start }}=1$ and $t_{\text {end }}=365$ for warm-season vegetation sites Here we don't intend to use $t_{\text {start }}\left(t_{\text {end }}\right)$ to denote the start (end) of the growing season.

The peak canopy photosynthetic capacity over a complete seasonal cycle of plant community photosynthesis and the day on which this peak occurs should contain useful information about the function of the vegetation and its interaction with the climate. We use $A_{P}$ to denote the peak canopy photosynthetic capacity:

$$
A_{P}=\max \left\{\left[A(t), \quad t_{\text {start }}<t<t_{\text {end }}\right]\right\}
$$

We use $t_{P}$ to denote the day on which the peak canopy photosynthetic capacity occurs. $t_{P}$ is called 'Peak Canopy Photosynthetic Capacity Day' or simply 'Peak Capacity Day'.

\subsubsection{Transitions Between Phases}

We name the transitions between the consecutive phases identified above 'Upturn Day' $\left(t_{U}\right)$, 'Stabilization Day' $\left(t_{S}\right)$, 'Downturn Day' $\left(t_{D}\right)$, and 'Recession Day' $\left(t_{R}\right)$, respectively. We set the upturn day at the intersection between the recovery line and the $x$-axis and the recession day at the intersection between the senescence line and the $x$-axis (Fig. 27.3). The upturn day and recession day are calculated from Eqs. (27.4) and (27.6), respectively, as follows:

$$
\begin{gathered}
t_{U}=t_{P R D}-A\left(t_{P R D}\right) / k_{P R R} \\
t_{R}=t_{P S D}-A\left(t_{P S D}\right) / k_{P S R}
\end{gathered}
$$


Fig. 27.3 Illustration of the five critical phenology phases for canopy photosynthesis

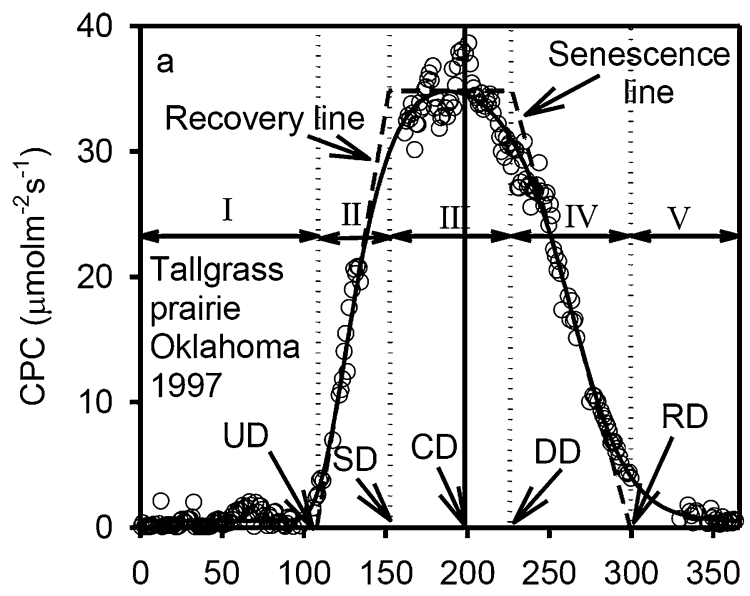

The stabilization day and downturn day are set at the days on which the peak canopy photosynthetic capacity $A_{P}$ is predicted to occur based on the RL equation (Eq. 27.4) and the SL equation (Eq. 27.6), respectively. These two dates are given by:

$$
\begin{aligned}
& t_{S}=t_{P R D}+\left[A_{P}-A\left(t_{P R D}\right)\right] / k_{P R R} \\
& t_{D}=t_{P S D}+\left[A_{P}-A\left(t_{P S D}\right)\right] / k_{P S R}
\end{aligned}
$$

We can also use the standard deviation of the "growing days" to measure the length of the growing season. To do so, we first define the mean or Center Day $\left(t_{C}\right)$ of the growing season as follows:

$$
t_{C}=\frac{\int_{t_{\text {start }}}^{t_{\text {end }}} t A(t) d t}{u}
$$

The standard deviation $\sigma$ of the 'growing days' from the center day of the growing season is:

$$
\sigma=\left(\frac{\int_{t_{\text {start }}}^{t_{\text {end }}}\left(t-t_{C}\right)^{2} A(t) d t}{u}\right)^{0.5}
$$

The length of the growing season can then be measured by the scaled standard deviation:

$$
L_{E}=2 \sqrt{3} \sigma
$$




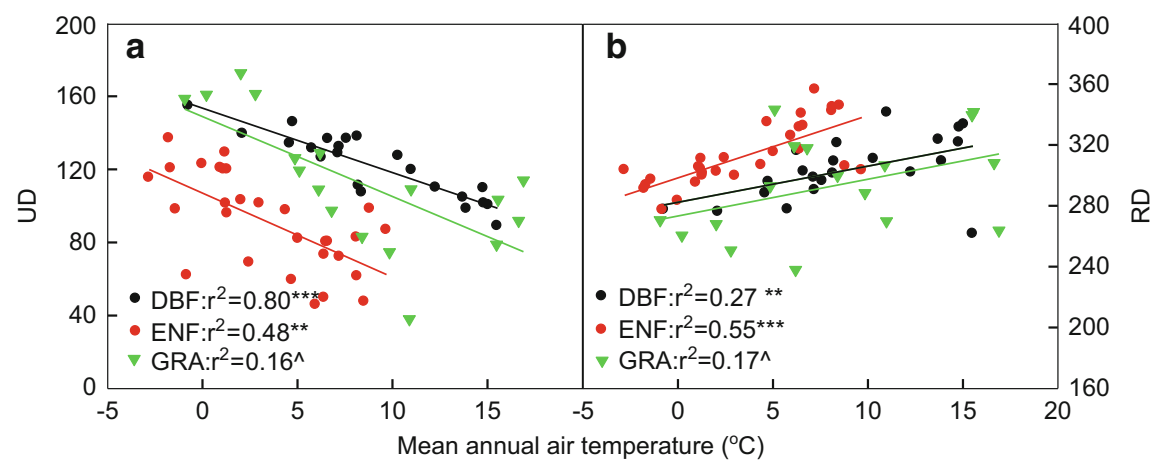

Fig. 27.4 The relationship between mean annual air temperature and upturning day $(U D)$ and recession day $(R D)$ for the three biomes. $D B F$ deciduous broadleaf forest, $E N F$ evergreen needle leaf forest, GRA grassland. ^, **, and *** represents the relationship was significant at $P<0.1$, 0.01 , and 0.001 levels, respectively

We name the scaled standard deviation the 'Effective Growing Season Length' and denote it by $L_{E}$. The scaling factor $2 \sqrt{3}$ is introduced so that $L_{E}$ is exactly the width if the temporal pattern of $A(t)$ is a rectangle (Gu et al. 2003). Gu et al. (2003) defined the center day as the 'center of gravity' of the curve $A(t)$. In the present paper, the center day is defined as a statistical mean and is thus more straightforward.

\subsection{Critical Phenology Indices in Response to Temperature Change}

Upturning day (UD) of canopy photosynthesis changed a lot across the sites. Air temperature was the dominant factor that controls the spring recovery of canopy photosynthesis in northern ecosystems. For all the three vegetation types, DBF, ENF, and GRS, the UD was negatively correlated with the mean annual air temperature (Fig. 27.4a). Sites with higher mean annual air temperature got to the UD much earlier than those with lower temperature. The slopes of the relationships were not significantly different among the biomes, suggesting a similar sensitivity of the UD in response to temperature change. In contrast, the recession day (RD) of canopy photosynthesis showed positive relationship with mean annual temperature across the sites (Fig. 27.4b). Sites with higher air temperature got to the RD much late than those with lower temperature.

Peak recovery day (PRD) of canopy photosynthesis varied among the three biomes, with the latest for evergreen needle leaf forest, and similarly earlier for deciduous broadleaf forest and grassland (Fig. 27.5a). Similar to the temperature response of UD, PRD was negatively correlated with mean annual air temperature. 


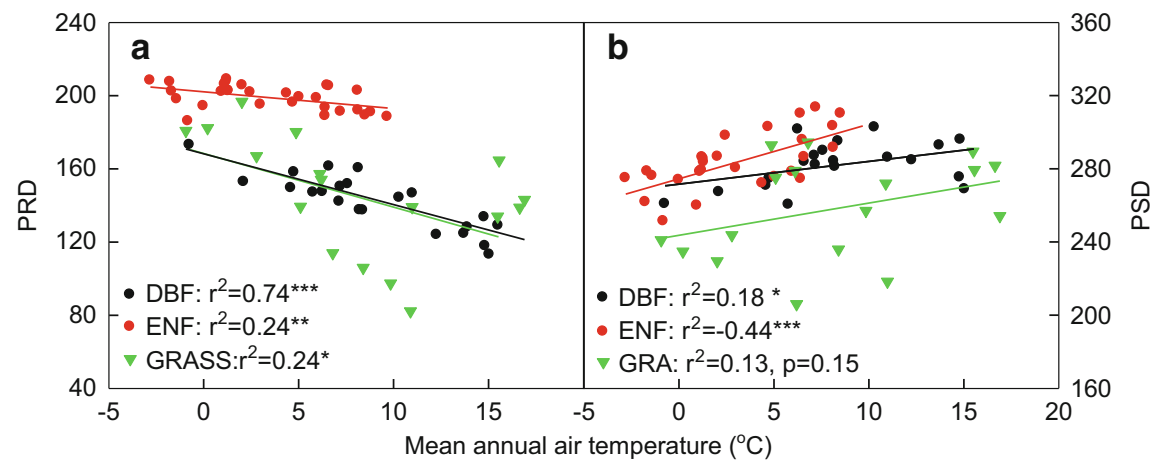

Fig. 27.5 The relationship between mean annual air temperature and peak recovery day $(P R D)$ and peak senescence day $(P S D)$ for the three biomes (see Fig. 27.4 for abbreviations)

Sites with higher air temperature got to the PRD much earlier than those with lower temperature. In contrast with the temperature response of PRD, peak senescence day (PSD) increased with mean annual air temperature. Sites with higher air temperature got to the PSD much later than those with lower temperature (Fig. 27.5b).

\subsection{Effective Growing Season Length and Photosynthetic Capacity in Response to Temperature Change and Controlling Annual GPP}

Due to the temperature response of beginning and ending days of canopy photosynthesis, the effective growing season length (Le) in the northern systems was also sensitive to temperature change. It increased with mean annual temperature for all the three biomes (Fig. 27.6a). Sites with higher mean annual air temperature had longer Le than those with lower temperature. The slope was much lower in grassland than that in ENF and DBF (Fig. 27.6a), suggesting that grassland was less sensitive to temperature in growing season length than ENF and DBF. Besides growing season length, peak canopy photosynthesis capacity (CPC) also showed positive linear relationship with mean annual air temperature (Fig. 27.6b), suggesting that photosynthetic capacity was also sensitive to temperature change in northern ecosystems.

In northern systems, both growing season length and photosynthetic capacity determine annual GPP (Fig. 27.7). Comparing with growing season length, peak CPC explained more of annual GPP changes across the sites (Fig. 27.7) for all the three biomes. 


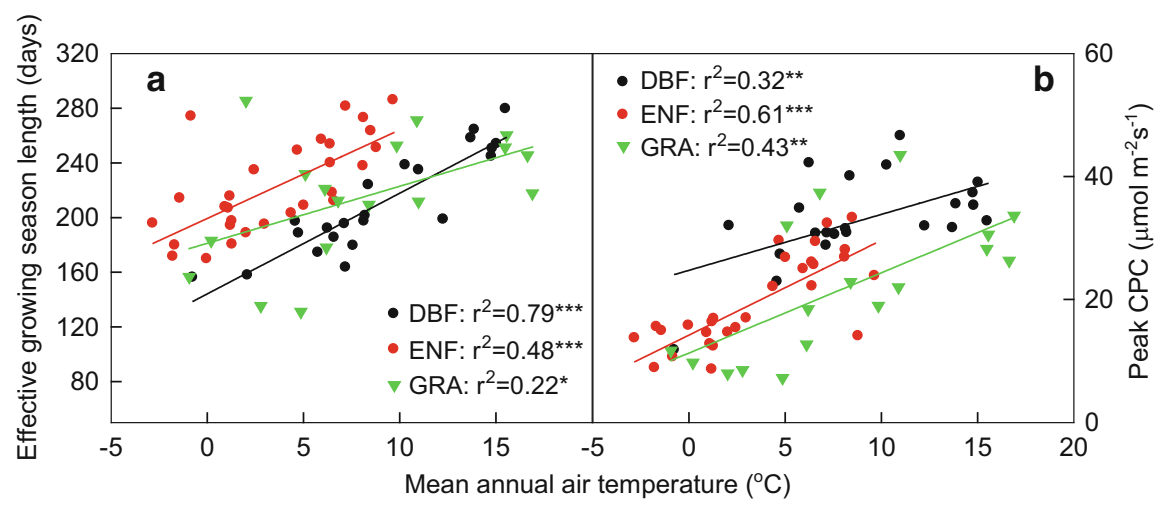

Fig. 27.6 The relationship between mean annual air temperature and effective growing season length (Le) and peak canopy photosynthesis capacity $(C P C)$ for the three biomes (see Fig. 27.4 for abbreviations)

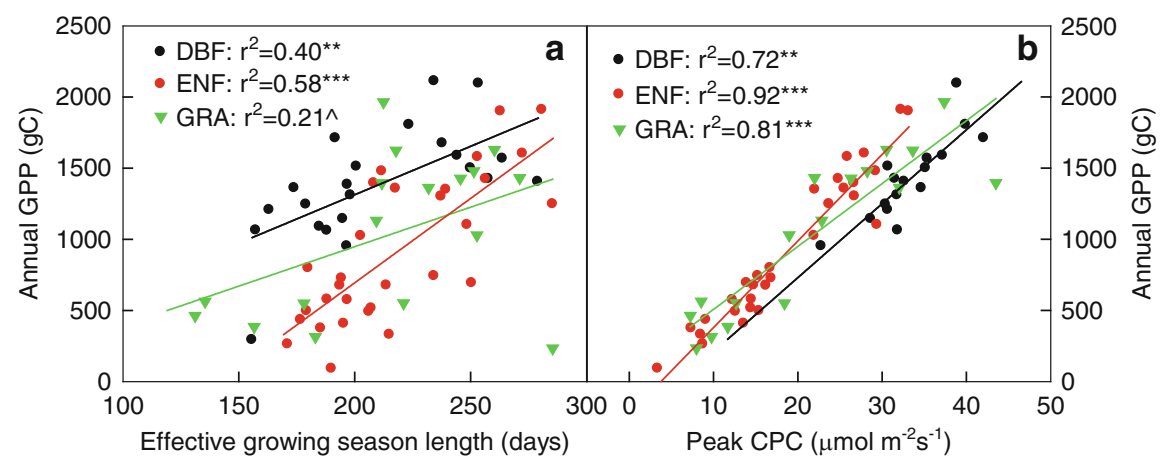

Fig. 27.7 The relationship of annual gross primary productivity $(G P P)$ with effective growing season length (Le) and peak canopy photosynthesis capacity $(C P C)$ for the three biomes (see Fig. 27.4 for abbreviations)

\subsection{Discussion and Conclusions}

\subsubsection{Temperature Sensitivity of Canopy Photosynthesis Phenology}

Phenology change is one of the most important factors affecting future vegetation productivity in response to rising global temperature. In this chapter we continued the effort initiated in Gu et al. (2003a, 2009) and explored the critical canopy photosynthesis phenology in response to temperature change. The spring recovery and fall recession phases derived from the seasonal dynamics of canopy photosynthesis showed the high sensitivity to temperature change. These phases reflect unique functioning of plant communities at different stages of the growing season. 
We found that the upturning day, peak recovery day, recession day, and peak senescence day of canopy photosynthesis all showed linear relationship with annual mean air temperature, suggesting the sensitivity of canopy photosynthesis phenology in response to temperature change in northern ecosystems.

Our results suggest that air temperature drives the changes in phenology of carbon uptake in the northern hemisphere. However, the recovery and senescence phenology showed different sensitivity to temperature changes. Spring phenology was more sensitive to temperature than fall phenology, which was reflected by the DOY changes vs temperature changes between the recovery phase and senescence phase. UD vs temperature had higher slopes than RD vs temperature, and PRD vs temperature had higher slopes than PRD vs temperature, for all the three biomes (Fig. 27.4). This suggests that early beginning of spring upturning day is more sensitive to temperature change than fall photosynthesis phenology. The higher temperature sensitivity of spring phenology than autumn was primarily due to that irradiances and temperatures are higher, and water is generally less limiting in spring than in autumn (Niu et al. 2011). Some previous studies also confirmed that the lengthening of the growing season by a certain number of days in spring stimulates ecosystem $\mathrm{C}$ uptake more than a lengthening by the same number of days in the fall (Kramer et al. 2000; Piao et al. 2007). This has been attributed also to greater radiative inputs and longer days, as well as better moisture availability as the result of snow melt and relative lower evaporative demand in spring than in fall (Black et al. 2000; Barr et al. 2004). So, the more sensitive spring phenology may favor carbon uptake in a warmer environment. Given the greater increase in the late winter and early spring temperatures than late spring and early summer temperature (Groisman et al. 1994), the advance of spring phenology should be even greater than the delay of fall. The advance of spring carbon uptake phenology and the delay of autumn carbon uptake phenology with increasing temperature indicate a longer growing season. Therefore, we expect a much greater carbon uptake in a warmer environment in the northern ecosystems due to the changes in canopy photosynthesis phenology.

Our results also showed that different vegetation types have different temperature sensitivity in phenology. Deciduous broadleaf forecast (DBF) and grassland was more sensitive to temperature changes when compared with evergreen needle leaf forest (ENF) in terms of peak recovery day. This is probably due to the life history strategy between the deciduous leaf and evergreen leaf. For DBF and grassland, the production of new foliage is a prerequisite for photosynthesis. The early recovery could be advantageous in terms of $\mathrm{C}$ uptake. By comparison, ENF strategy is more conservative. The recovery of photosynthesis in ENF is reversible, proceeds slowly and involves multiple steps (Monson et al. 2005). Different temperature sensitivities of biomes have important potential ecological consequences, especially in light of recent effects of climate change on species composition or vegetation changes. It is well known that species differ in their climatic determinants of phenology. Models also predict that because of this, species will respond in different ways to future climate change (Morin et al. 2008). The changes in vegetation or biomes under climate change or land use change will further modify ecosystem carbon cycle in response to temperature change. 


\subsubsection{Co-determination of Le and Peak CPC on Annual GPP}

It is generally assumed that warming will increase the length of the growing season (Penuelas and Filella 2001; Linderholm 2006) and thus stimulate primary productivity in boreal and temperate ecosystems (Baldocchi et al. 2001; Churkina et al. 2005; Baldocchi 2008; Dragoni et al. 2011). The observed links between Le and annual GPP in the northern hemisphere are consistent with the results in previous studies. We found that GPP will increase 5.5-11.8 $\mathrm{gCm}^{-2} \mathrm{day}^{-1}$ increase in growing season length (Fig. 27.7), which is in accordance with the model simulation (4.9-9.8 $\mathrm{gCm}^{-2} \mathrm{day}^{-1}$ in (Piao et al. 2007)) and $\left(8.5 \mathrm{gCm}^{-2} \mathrm{day}^{-1}\right.$ in (Euskirchen et al. 2006)). Our finding indicates that extending the growing season in a warmer environment partly contributes to the increase of terrestrial biomass storage in Northern Hemisphere. However, early spring and longer growing season does not always result in more carbon uptake. In some ecosystems, especially the water limited ecosystems, earlier onset of growing season may result from a shallow snowpack, leaving less moisture in the soil in summer and limiting plant growth later in the growing season (Hu et al. 2010).

While the growing season length affected how much $\mathrm{CO}_{2}$ could be potentially assimilated by a plant community over the course of a growing season, physiological processes such as the maximum photosynthetic capacity may also be important. We continued and extended our previous studies on regulation of peak CPC on canopy carbon assimilation potential (Gu et al. 2009). This study shows that both the effective growing season length of carbon uptake and the maximum carbon uptake capacity significantly determined the annual GPP in northern ecosystem, and peak CPC could even explain more changes in annual GPP than Le (Fig. 27.7). This indicates that the climate warming-induced changes in the growing season length largely but not totally contribute to the enhancement of terrestrial carbon uptake. Peak canopy photosynthetic capacity is also a good predictor for the canopy carbon assimilation potential. Peak CPC across the site was more related to temperature $\left(r^{2}=0.32,0.78\right)$ than precipitation $\left(r^{2}=0.14,0.33\right.$, respectively, for $\mathrm{DBF}$ and ENF) in DBF and ENF, and similarly related to temperature $\left(r^{2}=0.43\right)$ and precipitation $\left(r^{2}=0.45\right)$ in grassland, suggesting that temperature is also the dominant controlling factor for peak CPC in the northern ecosystems. To the best of our knowledge, this is the first evidence that reveals general controls of temperature on GPP in the northern hemisphere by influencing both phenological and physiological process of canopy photosynthesis.

The expanded analysis in this study allows us to develop a comprehensive understanding on how the photosynthetic phenology and physiology indices of plant community in response to temperature change and how the relationships change with vegetation types and seasons. The emergent patterns we observed of the co-determination of growing season length and canopy photosynthesis potential for carbon assimilation potentials in the northern hemisphere was well confirmed or established across the extended sites. These efforts are the starting point for 
developing ecosystem emergent properties and better understanding temperature sensitivity of ecosystem carbon uptake. It is worth noting that GPP is not observed and is rather estimated from the observed NEE, which means patterns reported here could be partly influenced by ER. However, it is unlikely that the temperature response of GPP phenology is caused by ER because either over- or underestimation of ER will not change phenological stages but possibly change peak CPC.

Given the rich datasets contained in the FLUXNET database, our study could easily be expanded to a wider range of sites. Because net ecosystem productivity follow a similar seasonal dynamics with GPP, the algorithm developed by Gu et al. (2003, 2009) could be applicable to examine NEP phenology, which directly reflects the ecosystem net carbon sequestration.

Acknowledgments This work was financially supported by the Terrestrial Carbon Program at the Office of Science, US Department of Energy, Grants DE-FG02-006ER64317 and DE-FG0201ER63198 and US National Science Foundation (NSF) grant DEB 0444518, DEB 0743778, DEB 0840964, DBI 0850290, and EPS 0919466 to YL. Oak Ridge National Laboratory (ORNL) is managed by UT-Battelle, LLC, for the U.S. Department of Energy under contract DE-AC05$00 \mathrm{OR} 22725$.

\section{References}

Baldocchi D (2003) Assessing the eddy covariance technique for evaluating carbon dioxide exchange rates of ecosystems: past, present and future. Global Change Biol 9(4):479-492

Baldocchi D (2008) Breathing of the terrestrial biosphere: lessons learned from a global network of carbon dioxide flux measurement systems. Aust J Bot 56:1-26

Baldocchi DD, Wilson KB (2001) Modeling CO2 and water vapor exchange of a temperate broadleaved forest across hourly to decadal time scales. Ecol Model 142(1-2):155-184

Baldocchi D, Falge E, Gu LH, Olson R, Hollinger D, Running S, Anthoni P, Bernhofer C, Davis K, Evans R, Fuentes J, Goldstein A, Katul G, Law B, Lee XH, Malhi Y, Meyers T, Munger W, Oechel W, KTP U, Pilegaard K, Schmid HP, Valentini R, Verma S, Vesala T, Wilson K, Wofsy S (2001) FLUXNET: a new tool to study the temporal and spatial variability of ecosystem-scale carbon dioxide, water vapor, and energy flux densities. Bull Am Meteorol Soc 82(11):2415-2434

Barr AG, Black TA, Hogg EH, Kljun N, Morgenstern K, Nesic Z (2004) Inter-annual variability in the leaf area index of a boreal aspen-hazelnut forest in relation to net ecosystem production. Agric Forest Meteorol 126(3-4):237-255. doi:10.1016/j.agrformet.2004.06.011

Barr A, Black A, McCaughey H (2009) Climatic and phenological controls of the carbon and energy balances of three contrasting boreal forest ecosystems in western Canada. In: Noormets A (ed) Phenology of ecosystem processes. Springer Science, New York

Black TA, Chen WJ, Barr AG, Arain MA, Chen Z, Nesic Z, Hogg EH, Neumann HH, Yang PC (2000) Increased carbon sequestration by a boreal deciduous forest in years with a warm spring. Geophys Res Lett 27(9):1271-1274

Churkina G, Schimel D, Braswell BH, Xiao XM (2005) Spatial analysis of growing season length control over net ecosystem exchange. Global Change Biol 11(10):1777-1787

Cleland EE, Chuine I, Menzel A, Mooney HA, Schwartz MD (2007) Shifting plant phenology in response to global change. Trends Ecol Evol 22(7):357-365. doi:10.1016/j.tree.2007.04.003 
Dragoni D, Schmid HP, Wayson CA, Potter H, Grimmond CSB, Randolph JC (2011) Evidence of increased net ecosystem productivity associated with a longer vegetated season in a deciduous forest in south-central Indiana, USA. Global Change Biol 17(2):886-897. doi:10.1111/j.1365-2486.2010.02281.x

Euskirchen ES, McGuire AD, Kicklighter DW, Zhuang Q, Clein JS, Dargaville RJ, Dye DG, Kimball JS, McDonald KC, Melillo JM, Romanovsky VE, Smith NV (2006) Importance of recent shifts in soil thermal dynamics on growing season length, productivity, and carbon sequestration in terrestrial high-latitude ecosystems. Global Change Biol 12(4):731-750. doi:10.1111/j.1365-2486.2006.01113.x

Falge E, Baldocchi D, Tenhunen J, Aubinet M, Bakwin P, Berbigier P, Bernhofer C, Burba G, Clement R, Davis KJ, Elbers JA, Goldstein AH, Grelle A, Granier A, Guomundsson J, Hollinger D, Kowalski AS, Katul G, Law BE, Malhi Y, Meyers T, Monson RK, Munger JW, Oechel W, Paw KT, Pilegaard K, Rannik U, Rebmann C, Suyker A, Valentini R, Wilson K, Wofsy S (2002) Seasonality of ecosystem respiration and gross primary production as derived from FLUXNET measurements. Agr Forest Meteorol 113(1-4):53-74. doi:Pii S0168-1923(02)00102-8

Goulden ML, Munger JW, Fan SM, Daube BC, Wofsy SC (1996) Exchange of carbon dioxide by a deciduous forest: response to interannual climate variability. Science 271(5255):1576-1578

Groisman PY, Karl TR, Knight RW (1994) Observed impact of snow cover on the heat-balance and the rise of continental spring temperatures. Science 263(5144):198-200

Gu L, Post WE, Baldocchi D, Black TA, Verma SB, Vesala T, Wofsy SC (2003) Phenology of vegetation photosynthesis. Phenology: an integrative environmental science, vol 39. Kluwer Academic Publishers, Dordrecht/Boston

Gu L, Post WM, Baldocchi DD, Black TA, Suyker AE, Verma SB, Vesala T, Wofsy SC (2009) Characterizing the seasonal dynamics of plant community photosynthesis across a range of vegetation types. Phenology of ecosystem processes. Springer, Dordrecht/New York

Hu J, Moore DJP, Burns SP, Monson RK (2010) Longer growing seasons lead to less carbon sequestration by a subalpine forest. Global Change Biol 16(2):771-783

Kramer K, Leinonen I, Loustau D (2000) The importance of phenology for the evaluation of impact of climate change on growth of boreal, temperate and Mediterranean forests ecosystems: an overview. Int J Biometeorol 44(2):67-75

Linderholm HW (2006) Growing season changes in the last century. Agr Forest Meteorol 137 (1-2):1-14. doi:10.1016/j.agrformet.2006.03.006

Menzel A, Fabian P (1999) Growing season extended in Europe. Nature 397(6721):659

Moffat AM, Papale D, Reichstein M, Hollinger DY, Richardson AD, Barr AG, Beckstein C, Braswell BH, Churkina G, Desai AR, Falge E, Gove JH, Heimann M, Hui DF, Jarvis AJ, Kattge J, Noormets A, Stauch VJ (2007) Comprehensive comparison of gap-filling techniques for eddy covariance net carbon fluxes. Agr Forest Meteorol 147(3-4):209-232. doi:10.1016/j. agrformet.2007.08.011

Monson RK, Sparks JP, Rosenstiel TN, Scott-Denton LE, Huxman TE, Harley PC, Turnipseed AA, Burns SP, Backlund B, Hu J (2005) Climatic influences on net ecosystem CO2 exchange during the transition from wintertime carbon source to springtime carbon sink in a highelevation, subalpine forest. Oecologia 146(1):130-147. doi:10.1007/s00442-005-0169-2

Morin X, Viner D, Chuine I (2008) Tree species range shifts at a continental scale: new predictive insights from a process-based model. J Ecol 96(4):784-794. doi:10.1111/j.1365-2745.2008. 01369.x

Niu SL, Luo YQ, Fei SF, Montagnani L, Bohrer G, Janssens IA, Gielen B, Rambal S, Moors E, Matteucci G (2011) Seasonal hysteresis of net ecosystem exchange in response to temperature change: patterns and causes. Global Change Biol 17(10):3102-3114. doi:10.1111/j.13652486.2011.02459.x

Papale D, Reichstein M, Aubinet M, Canfora E, Bernhofer C, Kutsch W, Longdoz B, Rambal S, Valentini R, Vesala T, Yakir D (2006) Towards a standardized processing of net ecosystem 
exchange measured with eddy covariance technique: algorithms and uncertainty estimation. Biogeosciences 3(4):571-583

Penuelas J, Filella I (2001) Phenology - responses to a warming world. Science 294 (5543):793-795

Piao SL, Friedlingstein P, Ciais P, Viovy N, Demarty J (2007) Growing season extension and its impact on terrestrial carbon cycle in the Northern Hemisphere over the past 2 decades. Global Biogeochem Cycles 21(3):1-11. doi:10.1029/2006gb002888

Piao SL, Ciais P, Friedlingstein P, Peylin P, Reichstein M, Luyssaert S, Margolis H, Fang JY, Barr A, Chen AP, Grelle A, Hollinger DY, Laurila T, Lindroth A, Richardson AD, Vesala T (2008) Net carbon dioxide losses of northern ecosystems in response to autumn warming. Nature 451(7174):49-U43. doi:10.1038/Nature06444

Schwartz MD, Ahas R, Aasa A (2006) Onset of spring starting earlier across the Northern Hemisphere. Global Change Biol 12(2):343-351. doi:10.1111/j.1365-2486.2005.01097.x

Sherry RA, Zhou X, Gu S, Arnone JA, Schimel DS, Verburg PS, Wallace LL, Luo Y (2007) Divergence of reproductive phenology under climate warming. Proc Natl Acad Sci USA 104 (1):198-202

Yu H, Luedeling E, Xu J (2011) Winter and spring warming result in delayed spring phenology on the Tibetan Plateau. Proc Natl Acad Sci USA 45:1-6. doi:10.1073/pnas.1012490107 